\title{
Comparison of polymers and ceramics in new and discarded electrical insulators: reuse and recycling possibilities
}

\author{
Vanessa Alves Mantovani, ${ }^{1}$, Camila Silva Franco ${ }^{2}$, \\ Sandro Donnini Mancini ${ }^{1}$, Haroldo L Haseagawa ${ }^{3}$, \\ Bruno Fernando Gianelli ${ }^{4}$, Vladimir Xavier Batista ${ }^{5}$, \\ Luciane Lopes Rodrigues ${ }^{6}$
}

\author{
${ }^{1}$ Universidade Estadual Paulista "Júlio de Mesquita Filho" UNESP - Campus Experimental de Sorocaba. Avenida Três \\ de Março, 511. Alto da Boa Vista CEP 18087-180 - Sorocaba - SP \\ e-mail: vanessa.alves.mantovani@ hotmail.com; mancini@ sorocaba.unesp.br \\ ${ }^{2}$ Universidade Federal de Lavras UFLA - Campus universitário, Departamento de Engenharia, Núcleo Didático Científi- \\ co de Água e Solo, CEP 37200-000, Lavras - MG \\ e-mail: camilasilvafranco@posrad.ufla.br \\ ${ }^{3}$ Universidade de Sorocaba. UNISO - Cidade Universitária. Rodovia Raposos Tavares km 92,5. Vila Artura. CEP 18023- \\ 000 - Sorocaba - SP \\ e-mail: haroldo.hasegawa@prof.uniso.br \\ ${ }^{4}$ Instituto Federal de Educação, Ciência e Tecnologia de São Paulo. IFSP. Avenida João Olímpio de Oliveira, 1561. CEP \\ 18202-000. Itapetininga- SP \\ e-mail: brunogianelli@gmail.com \\ 5 AES Eletropaulo. Rua do Lavapés, 463. Cambuci. CEP 01519-000. São Paulo - SP \\ e-mail: vladimir.xavier@aes.com \\ ${ }^{6}$ Faculdade de Tecnologia. FATEC - Campus Sorocaba. Av. Engenheiro Carlos Reinaldo Mendes, 2015 - Alto da Boa \\ Vista. CEP 18013-900 - Sorocaba - SP \\ e-mail: lulopesrodrigues@gmail.com
}

\begin{abstract}
The expansion and maintenance of electricity distribution networks generates large amounts of waste, much of it in the form of discarded insulators that are not reused or recycled. This paper describes the results of tests on used and new ceramic and polymeric insulators to verify if their exposure to weathering justifies their replacement. In new and used ceramic insulators, properties such as contact angle, relative density, porosimetry, dilatometry and X-ray diffraction patterns showed no differences or the differences that were found could not be related to their use. The discarded ceramic material showed high thermal stability, an interesting characteristic for application as chamotte. It can also be reused to replace gravel used in substations. In polymeric insulators, thermogravimetry, differential scanning calorimetry and relative density test results suggest degradation of used material compared to new. This would justify their replacement and discard as waste, but they show little recycling potential.
\end{abstract}

Keywords: Electricity Network Distribution Wastes, Reuse, Recycling, Characterization Ceramics, Polymers.

\section{INTRODUCTION}

Electricity distribution networks are usually very dynamic and often quite old. New gated communities and businesses, for example, often require new networks to serve them, and existing networks may be upgraded according to previously established schedules. In addition, pointwise power outages and voltage and current oscillations may require interventions. In all these situations, electricity distribution networks require new components such as wires, cables, poles, braces, crossarms, switches and insulators, as well as other items.

In many cases, particularly in the upgrading of distribution lines and replacements during preventive or corrective maintenance, large amounts of wastes are generated and many of them appear to be in good conditions. These components are discarded because replacing them with new ones is usually considered simpler, faster, more efficient and inexpensive than performing in situ tests on each component to determine the cause of a possible problem.

The waste generated in these cases can be divided into three basic types: 1) a highly valued one in recycling market, such as the copper and aluminum of wires and cables; 2) a less valued one but for which there is a 
market, as in the case of iron, steel and some types of thermoplastics; and 3) a type of waste not valued and without a market, which is the case of ceramics and some polymeric materials [1].

With regard to the latter type, attention should be given to insulators, which are usually made of elastomers, glass, or traditional clay, kaolin and flux-based ceramic (the latter commonly called porcelain). Albeit possible, the reuse of discarded insulators or part of them is unlikely. This is not only due to the need for individual tests to check for possible defects but also due to the relatively low price of similar new parts and the rough handling that used insulators are subjected to after their removal from the network (which can impair their surface and thus their properties). Nevertheless, perhaps the main reason why these parts are not reused is that the agency that regulates this sector in Brazil does not encourage this type of practice, and the assets of the utility company that chooses to do so may even be devaluated.

To exemplify the volume of insulators discarded and sold as scrap, just one company which supplies power to the metropolitan region of São Paulo - the electricity utility power company AES/Eletropaulo, discarded 677 tons of insulators in 2011, representing approximately $14 \%$ of all the wastes generated in the maintenance and expansion of its distribution network. Studies about the composition of these components [1] found that slightly more than 82 tons are in the form of glass, 591 tons are porcelains and 4 tons are polymeric materials.

This paper presents and discusses the results of the characterization of new and used ceramic (porcelain) and polymeric insulator materials, to verify if their use led to degradation that could change their final properties and justify their replacement. Current market opportunities and the recycling potential of each type of scrap are also discussed.

\section{MATERIALS AND METHODS}

\subsection{Sampling}

Used polymer and ceramic insulators were collected from the scrapyard of an electric utility company in São Paulo, and new insulators of the same model from the company's warehouse. The insulator models were long rod polymer and ceramic column type insulators (gray colored glaze), both $15 \mathrm{kV}$. Figure 1 shows photographs of the insulators, including their metal coupling fittings. Although they are less frequently discarded than the ceramic models, the polymeric insulators were chosen because they are among the models most commonly purchased by the company for replacement and for new projects. The ceramic (porcelain) insulators, in turn, were chosen because of their constant presence in the company's scrap, according to a previous survey [1].
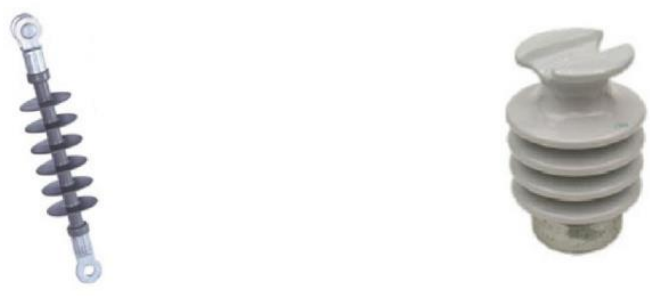

Figure 1: (a) long rod polymer insulator, (b) ceramic column insulators

Samples of about $1 \mathrm{~cm} 2$ were removed from the rims of used polymeric insulators, and of 1.5 to $2 \mathrm{~cm} 2$ with a thickness of 3 to $20 \mathrm{~mm}$ from both the glazed part (external) and the ceramic body (internal) of used ceramic insulators. The samples were subjected to a series of tests illustrated in Figure 2. Prior to these tests, the ceramic samples were washed with deionized water and oven-dried at $110^{\circ} \mathrm{C}$ for 24 hours. The polymer samples were subjected to a similar procedure also prior to testing, with oven-drying substituted for natural air drying for 7 days.

\subsection{Tests performed on Polymers and Ceramics}

The polymer samples were gold-coated and analyzed by scanning electron microscopy (SEM), using a FEI QUANTA Inspect S microscope in the Metals Laboratory of INA-Schaeffler Brazil. Several points were evaluated by X-ray energy dispersive spectroscopy (EDS) using an INCA x-sight detector to determine their 
chemical composition.

The ceramic samples (also gold-coated) were examined in a Philips XL-30 FEG scanning electron microscope coupled to an energy dispersive spectrometer (EDS) in the Structural Characterization Laboratory at the Department of Materials Engineering of the Federal University of São Carlos.

The contact angle was determined based on the paper of Hoch, Mahatho \& Bologna, from samples taken from three different parts of each insulator (upper, middle and bottom). The reason for this procedure is that the effect of the electromagnetic field along the length of a polymeric insulator can seriously affect the properties of the elastomer as a function of electric field to which it is subjected [2]

To determine the contact angle, after the initial wash described in section 2.1, the samples were placed in a beaker with distilled water and subjected to an ultrasonic bath for 15 minutes, after which they were dried at room temperature. Using a Ramé-Hart 100-00 goniometer in the Plasma Technology Laboratory - LaPTec at UNESP at Sorocaba, 5 drops of approximately $10 \mu \mathrm{L}$ of deionized water were deposited on the surface of a sample and 20 measurements were taken of the contact angle of the droplets on the surface.

The relative density determined by the liquid displacement method was performed at the Polymer Laboratory of the company INA-Schaeffler Brazil in Sorocaba, using an analytical balance coupled to a support, in which the sample masses were measured in air and submerged in water, according to the ASTM D531 standard [3] .

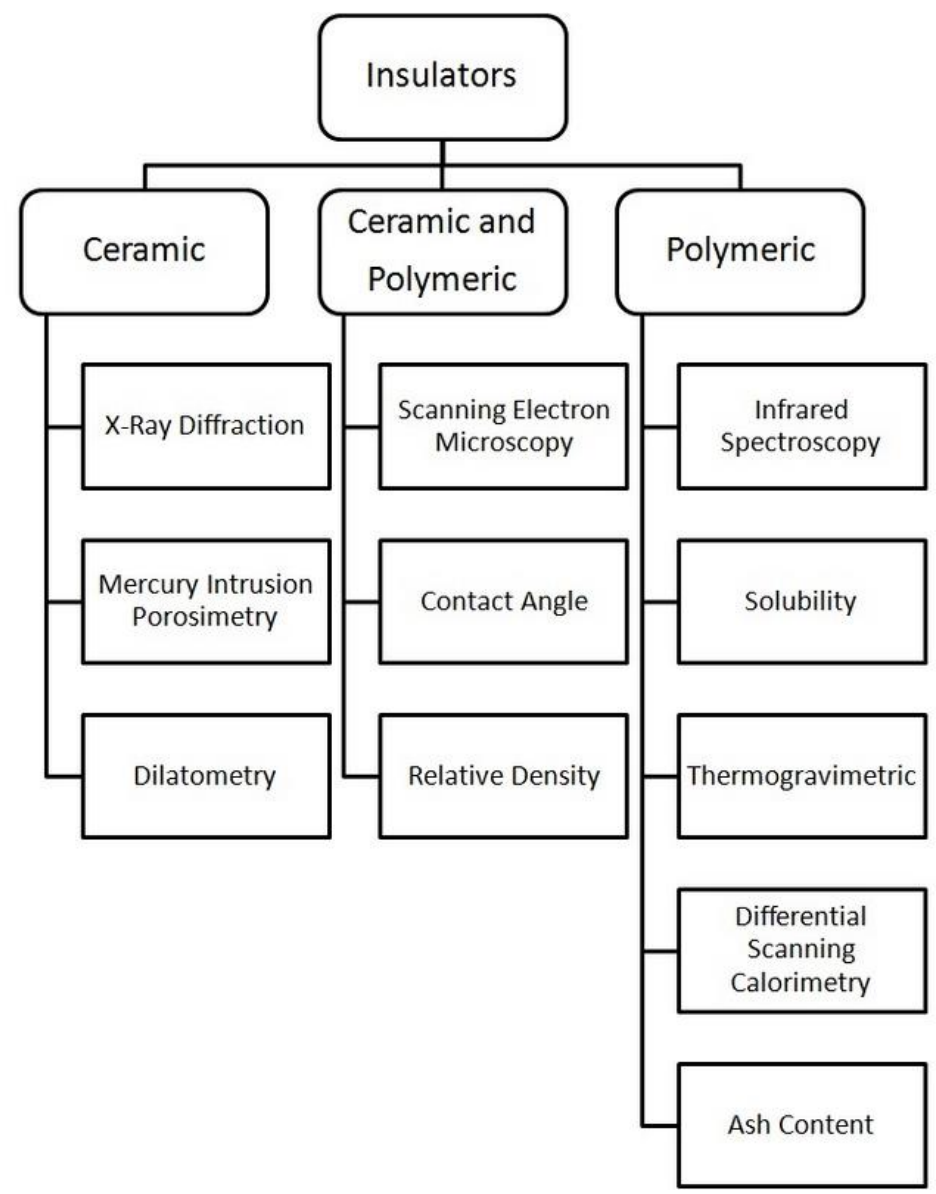

Figure 2: Tests performed on the polymeric and ceramic materials contained in the new and used insulators

\subsection{Tests performed only on Ceramics}

The X-ray diffraction (XRD), mercury intrusion porosimetry and dilatometry tests of the ceramic materials were performed at the Ceramics Laboratory of the Department of Materials Engineering at the Federal University of São Carlos. For the X-ray diffraction test, the samples of ceramic body were ground in a mortar and sifted through a 325 mesh sieve. The measurements were taken at room temperature in a Siemens D5000 diffractometer equipped with a copper tube, with a $40 \mathrm{kV}$ x $40 \mathrm{~mA}$ power supply, and a filtration system 
comprising a secondary curved graphite monochromator. The samples were subjected to X-rays in the range of $2 \square$ between $5^{\circ}$ and $100^{\circ}$, at a scan rate of $0.33^{\circ}$ per minute, and the phases in the samples were identified from the resulting spectra.

In the mercury intrusion porosimetry test, samples of approximately $0.5 \mathrm{~g}$ of ceramic body were analyzed in a mercury porosimeter (Aminco, USA), which allows for testing using a filling pressure of 0 to 5000 psi.

The dilatometry test involved the analysis of samples of ceramic body in a Norton model 1400 Dilatometer (USA), equipped with an aluminum oxide (A12O3) tube, in ambient atmosphere, at a maximum temperature of $1100^{\circ} \mathrm{C}$ and a heating rate of $5^{\circ} \mathrm{C} / \mathrm{min}$. Graphs were plotted from the thermal expansion vs. temperature curves, and the dilatometric coefficient or linear thermal expansion coefficient was calculated based on the slope of the initial part of the curves.

\subsection{Test performed only on Polymers}

The polymer in new and used insulators was identified using a JASCO model 410 Fourier transform infrared spectrophotometer (FTIR) in the Plasma Technology Laboratory (UNESP at Sorocaba), equipped with a HATR MIRacleTM horizontal single attenuated total reflectance accessory (ATR). This test is required because insulators for electric power distribution are usually made of poly (dimethyl siloxane),commonly called silicone rubber, EPDM (ethylene propylene diene monomer) rubber or high density polyethylene.

After the polymer was identified, solubility tests were performed with pieces of about $10 \mathrm{mg}$ each in $100 \mathrm{~mL}$ of the solvents described in the literature as suitable for the material [4].

Thermogravimetric analyses were conducted under an inert gas atmosphere (nitrogen, N2) in a NETZSCH TG-209-F1 Phoenix ${ }^{\circledR}$ thermogravimetric analyzer at the Polymer Laboratory of INA-Schaeffler in Sorocaba, according to the ASTM E1131 standard [5] . The heating rate applied was $30^{\circ} \mathrm{C} / \mathrm{min}$ in a range of 30 to $350^{\circ} \mathrm{C}$, followed by a 10 -minute isotherm at the latter temperature, and further heating at the same rate up to $750^{\circ} \mathrm{C}$, remaining at this temperature for 15 minutes until the end of the test.

New and used polymers were also analyzed by differential scanning calorimetry (DSC) in a NETZSCH DSC-204-F1 Phoenix ${ }^{\circledR}$ calorimeter at the Polymer Laboratory of INA-Schaeffler in Sorocaba, according to the ASTM D3418 standard [6]. An inert nitrogen gas atmosphere was used, and the system's temperature was reduced at a rate of $25^{\circ} \mathrm{C} / \mathrm{min}$ from $25^{\circ} \mathrm{C}$ to $-180^{\circ} \mathrm{C}$, held at that temperature for 2 minutes, and then heated to $30^{\circ} \mathrm{C}$ at a rate of $10^{\circ} \mathrm{C} / \mathrm{min}$.

The ash content in the polymer was determined at UNESP Sorocaba in a Quimis Q-318M24 muffle furnace, as established by the ASTM D 5630 standard [7]. Approximately $2.5 \mathrm{~g}$ of sample in a crucible was placed on a Bunsen burner to extinguish any trace of flame. The crucible was then heated in a muffle furnace at $800^{\circ} \mathrm{C}$ for 75 minutes, cooled in a desiccator and weighed on an analytical balance. After this procedure, the crucible was heated again in the muffle furnace at $800^{\circ} \mathrm{C}$, but this time for 30 minutes, then cooled and weighed. The total mass of the crucible and sample was only considered constant when there was a difference of no more than $5 \mathrm{mg}$ between the two weighings. Otherwise, heating in the muffle furnace for 30 minutes, followed by cooling and weighing, was repeated.

\section{RESULTS}

\subsection{Ceramic Insulators}

Figure 3 shows SEM micrographs of fractured surfaces of the inner part (ceramic body) of both new and used ceramic insulators. 

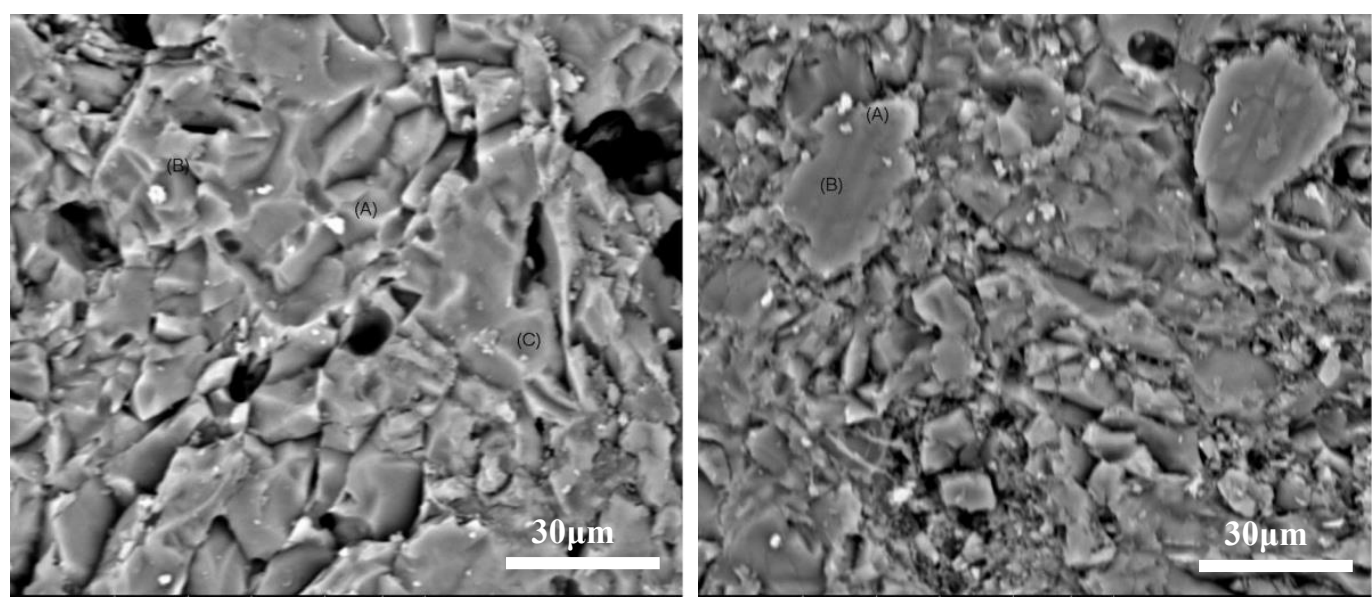

Figure 3: SEM micrographs of the inner part (ceramic body) samples of new (a) and used (b) ceramic insulators

Figure 3 shows a dense and homogeneous microstructure with a grain size of approximately $30 \mu \mathrm{m}$. The pores are attributed to grains removed during the fracture process. A comparison of new and used materials showed no significant surface changes. Table 1 describes the chemical compositions in mass of each atom determined from an analysis of the EDS-SEM micrographs.

Table 1: Chemical compositions of the samples of new and used ceramic (ceramic body) obtained by SEM/EDS

\begin{tabular}{c|c|c}
\hline \multirow{2}{*}{ Element } & \multicolumn{2}{|c}{ in mass\% } \\
\cline { 2 - 3 } & New sample (Figure 3a) & Used sample (Figure 3b) \\
\hline $\mathrm{O}$ & 41,68 & 38,2 \\
$\mathrm{Na}$ & 0,92 & 0,6 \\
$\mathrm{Al}$ & 9,68 & 15,4 \\
$\mathrm{Si}$ & 34,77 & 33,1 \\
$\mathrm{~K}$ & 4,24 & 3,6 \\
$\mathrm{Fe}$ & 0,85 & - \\
$\mathrm{Ca}$ & - & 1,3 \\
\hline
\end{tabular}

Table 1 indicates that the elements found in the highest quantities were oxygen, silicon and aluminum. This was expected, since silica ( $\mathrm{SiO} 2$ ) and alumina (A12O3) are common constituents in most ceramic materials and particularly in the chemical composition of ceramic insulators. The detected iron is considered a natural contaminant of clay, while sodium and potassium are probably from the feldspar and fluxing agents employed to increase the densification of the ceramic and reduce its sintering time. Figure 4 shows SEM images of the glazes of samples of new and used ceramic insulators. 


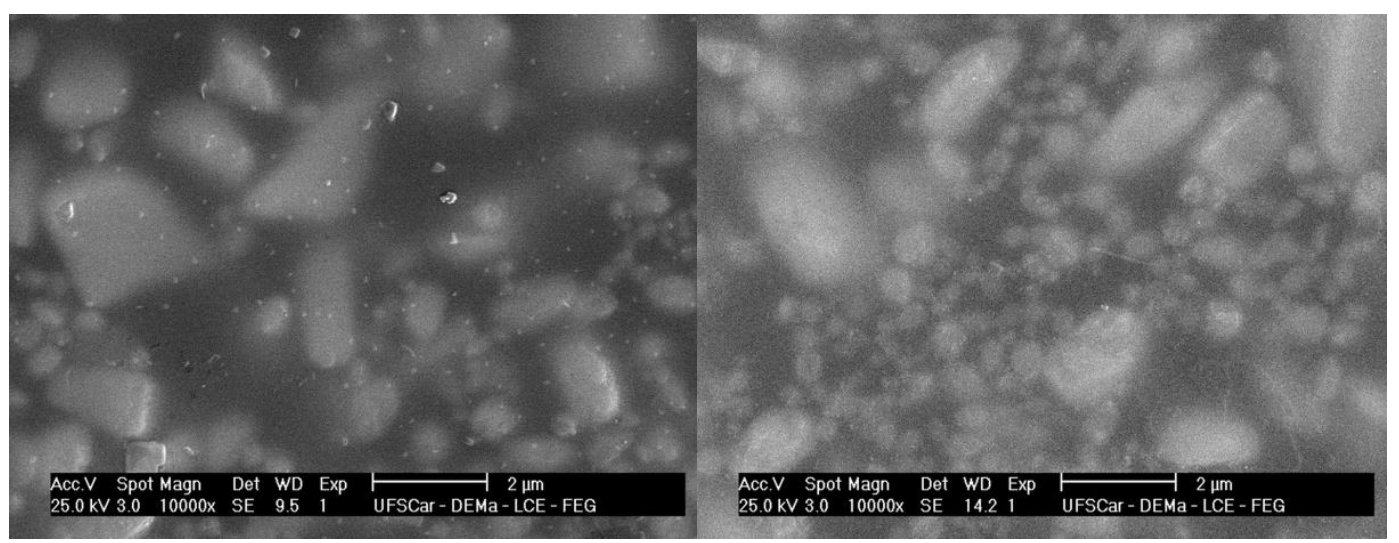

Figure 4: SEM micrographs of glazed surfaces of (a) new, and (b) used ceramic samples

A visual examination of Figure 4 reveals differences between the new and used samples, although none of them showed cracks or intrusions. The images suggest that both samples are highly homogeneous glazes, which indicates that the integrity of the glazed surface was preserved during use. Crystal formations were also observed, probably zircon $(\mathrm{ZrSiO} 4)$, which is commonly found in glazes to improve the abrasive strength, as a waterproofing agent and opacifier (white color) [ㅇ-어. Table 2 describes the chemical compositions of the glaze samples obtained by SEM/EDS.

Table 2: Chemical composition of glaze of used and new ceramic samples obtained by SEM/EDS

\begin{tabular}{c|c|c}
\hline \multirow{2}{*}{ Element } & \multicolumn{2}{|c}{ in mass\% } \\
\cline { 2 - 3 } & New sample (Figure 4a) & Used sample (Figure 4b) \\
\hline $\mathrm{O}$ & 36,64 & 24,19 \\
$\mathrm{~K}$ & 3,69 & 4,5 \\
$\mathrm{Si}$ & 38,2 & 42,49 \\
$\mathrm{Al}$ & 5,04 & 5,41 \\
$\mathrm{Fe}$ & 0,11 & 0,82 \\
$\mathrm{Ca}$ & 3,97 & 5,61 \\
$\mathrm{Zr}$ & 12,35 & 16,98 \\
\hline
\end{tabular}

Table 3 presents the contact angle test results on the glaze of ceramic insulators. As can be seen, the ceramic samples have hydrophilic characteristics (contact angle lower than $90^{\circ}$ ), as expected and as illustrated in Figure 5.

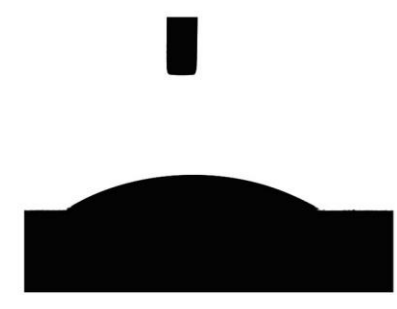

Figure 5: Image of droplets deposited on the surface of ceramic glaze 
MANTOVANI, V. A.; FRANCO, C. S; MANCINI, S. D.; HASEAGAWA, H. L.; GIANELLI, G. F.; BATISTA, V. X.; RODRIGUES, L. L. Revista Matéria, v. 18, n. 04, pp. 1549 - 1562, 2013.

Table 3: Contact angle of the samples of ceramic insulators

\begin{tabular}{c|c|c}
\hline \multicolumn{2}{c|}{ Sample } & Contact angle $\left(^{\circ}\right)$ \\
\hline \multirow{2}{*}{ Ceramic (glaze) } & New & $58.97 \pm 2.06$ \\
& Used & $47.95 \pm 2.23$ \\
\hline
\end{tabular}

One reason for the behavior shown in Table 3 and Figure 5 is the chemical composition of the surfaces: ceramic materials have inorganic chains with a polar tendency and hence have affinity for water. Furthermore, ceramic glazes typically contain inorganic additives that help to further decrease their contact angle, which was also confirmed by Prette [10].

Figure 6 shows the XRD spectra of samples of new and used ceramic body.

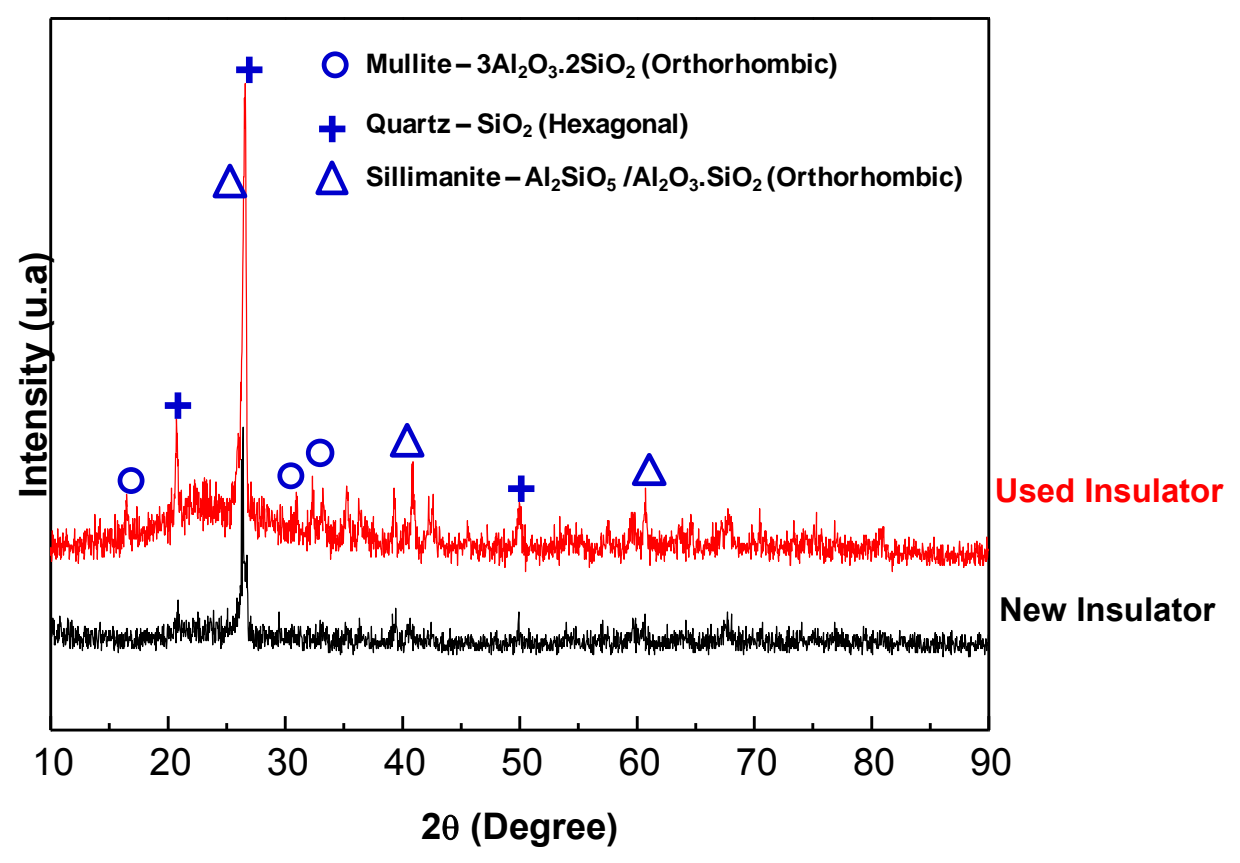

Figure 6: XRD spectra of samples of ceramic body

The curves in Figure 6 reveal appreciable levels of noise, suggesting the presence of amorphous (glassy) phases from the sintering reaction of $\mathrm{SiO} 2$ and fluxing agents (especially $\mathrm{Na}$ and $\mathrm{K}$ ) contained in the ceramic body. This is also a strong indication of the occurrence of liquid phase sintering during production, which provides high density and low porosity, that are useful characteristics for ceramics used in insulators. The presence of quartz, mullite and sillimanite phases was detected in the two samples.

The relative density of the ceramic insulators showed no variation in specific mass, and the results for both the new and used samples were $2.350 \mathrm{~g} / \mathrm{cm} 3( \pm 0.001)$ and $2.330 \mathrm{~g} / \mathrm{cm} 3( \pm 0.010)$, respectively. It is noteworthy that the similarity of these results suggests the absence of open porosity or cracks in material, as seen in the porosimetry test results.

Even under pressures of up to $5000 \mathrm{psi}$, all the samples showed zero absorption of mercury in the porosimetry test including the used samples, i.e., the tested samples showed no porosity. This finding confirms the relative density test results. In fact, non-porosity is a requirement for electrical insulators, since moisture embedded in the pores would impair their insulation characteristics. It should be kept in mind that this test was performed on the inner part of the insulator (ceramic body).

Table 4 lists the dilatometric coefficients of the initial portion of the linear thermal expansion curve (100 to $800^{\circ} \mathrm{C}$ ) as a function of the temperature generated in the dilatometric test. It was found that the curves genera- 
MANTOVANI, V. A.; FRANCO, C. S; MANCINI, S. D.; HASEAGAWA, H. L.; GIANELLI, G. F.;

BATISTA, V. X.; RODRIGUES, L. L. Revista Matéria, v. 18, n. 04, pp. 1549 - 1562, 2013.

ted during the test showed the same pattern, i.e., stabilization of the expansion and beginning of contraction occurred at close to $900^{\circ} \mathrm{C}$, indicating the transformation of $\alpha$ quartz to $\beta$ quartz.

Table 4: Coefficient of linear thermal expansion of ceramic insulator samples

\begin{tabular}{c|c|c}
\hline Sample & $\alpha\left(10^{-6}\right)$ & $\Delta \mathrm{T}\left({ }^{\circ} \mathrm{C}\right)$ \\
\hline New & 5,12 & 100 a 800 \\
Used & 5,75 & 100 a 800 \\
\hline
\end{tabular}

The phases observed during the dilatometric tests were stable, indicating that the sintering performed in the manufacturing process of the insulators was good.

\subsection{Polymer Insulators}

The polymer from which the new and old insulators used by the electric utility company are made was identified in an infrared spectroscopy, whose spectra are shown in Figure 7. The new and old samples both showed the typical absorption bands of poly (dimethyl siloxane) [4]:
- $\quad \mathrm{Si}\left(\mathrm{CH}_{3}\right)_{2}-\mathrm{O}-\mathrm{Si}\left(\mathrm{CH}_{3}\right)_{2^{-}}$at $2905-2960 \mathrm{~cm}^{-1}, 1020 \mathrm{~cm}^{-1}$ and $1090 \mathrm{~cm}^{-1}$;
- $\quad \mathrm{Si}\left(\mathrm{CH}_{3}\right)_{3}$ at $2905-2960 \mathrm{~cm}^{-1}, 1250 \mathrm{~cm}^{-1}, 840 \mathrm{~cm}^{-1}$ and $765 \mathrm{~cm}^{-1}$;
- $\quad \mathrm{Si}\left(\mathrm{CH}_{3}\right)_{2}$ at $2905-2960 \mathrm{~cm}^{-1}, 1260 \mathrm{~cm}^{-1}, 855 \mathrm{~cm}^{-1}$ and $805 \mathrm{~cm}^{-1}$;
- $\quad \mathrm{Si}-\mathrm{CH}_{3}$ at $2905-2960 \mathrm{~cm}^{-1}, 1245-1275 \mathrm{~cm}^{-1}$ and $760-845 \mathrm{~cm}^{-1}$;
- $\quad \mathrm{Si}-\mathrm{H}$ at $2100-2300 \mathrm{~cm}^{-1}$ and $760-910 \mathrm{~cm}^{-1}$;
- $\quad \mathrm{Si}-\mathrm{OH}$ at $3695 \mathrm{~cm}^{-1}, 3200-3400 \mathrm{~cm}^{-1}$ and $810-960 \mathrm{~cm}^{-1}$;
- $\mathrm{Si}-\mathrm{CH}=\mathrm{CH}_{2}$ at $1590-1610 \mathrm{~cm}^{-1}, 1410 \mathrm{~cm}^{-1}, 990-1020 \mathrm{~cm}^{-1}$ and $940-980 \mathrm{~cm}^{-1}$.

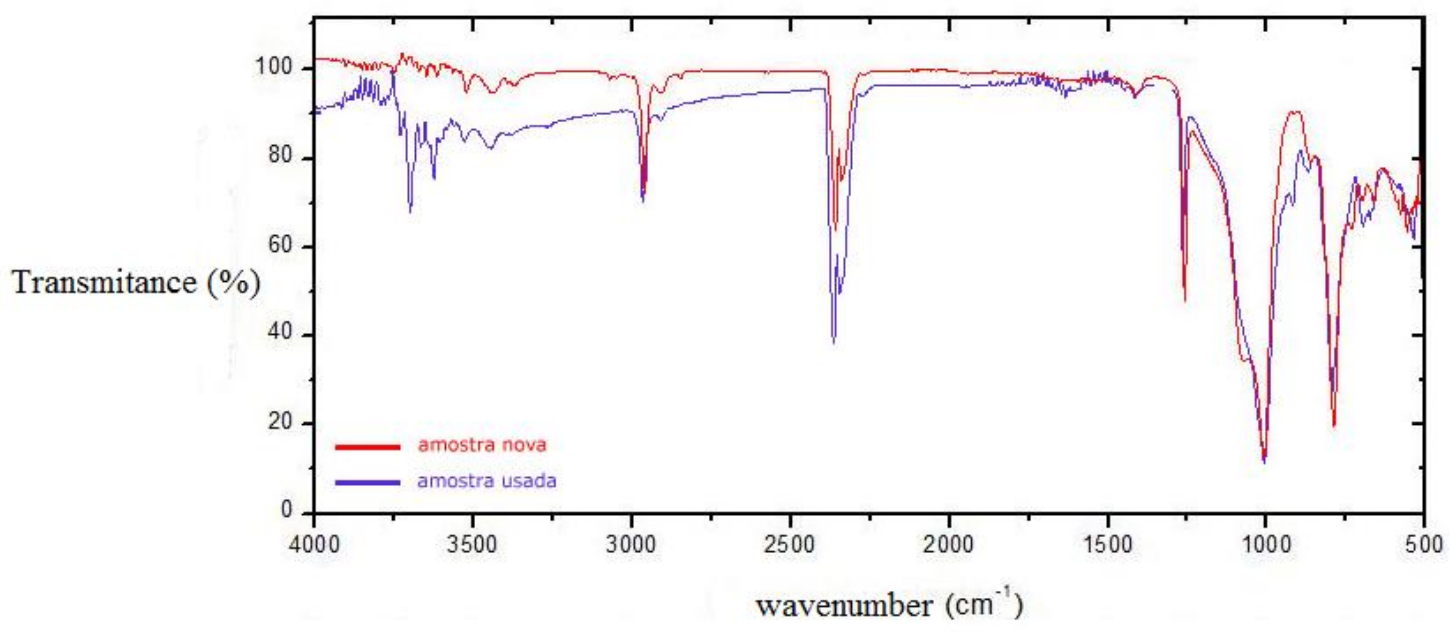

Figure 7: Overlaid infrared spectra of a new and a used sample of the polymer insulator

Figure 8 shows SEM micrographs of samples of new and used polymeric insulators. The chemical composition at two points in each image was analyzed by EDS, one in the matrix (background) and the other in the incrustations (parts in high relief). Table 5 lists the chemical composition in the regions of the highlighted points, which was determined from the EDS/SEM spectra. 
MANTOVANI, V. A.; FRANCO, C. S; MANCINI, S. D.; HASEAGAWA, H. L.; GIANELLI, G. F.; BATISTA, V. X.; RODRIGUES, L. L. Revista Matéria, v. 18, n. 04, pp. 1549 - 1562, 2013.
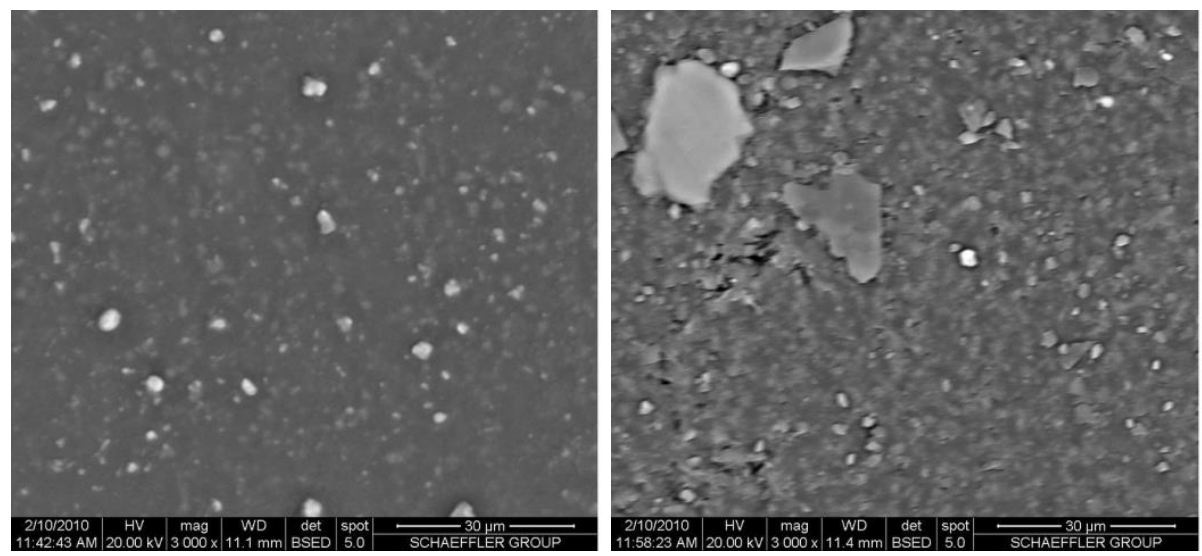

Figure 8: SEM micrographs of the surface of samples of new (a) and used (b) polymer insulators

Table 5: Chemical composition of samples of new and used polymer insulators at the points highlighted in Figure 8, determined by SEM/EDS

\begin{tabular}{c|c|c|c|c}
\hline \multirow{2}{*}{ Element } & \multicolumn{2}{|c|}{ New insulator (Figure 8a) } & \multicolumn{2}{c}{ Used insulator (Figure 8b) } \\
\cline { 2 - 5 } & \multicolumn{2}{|c|}{ in mass\% } & \multicolumn{2}{|c}{ in mass\% } \\
\cline { 2 - 5 } & Matrix & Incrustation & Matrix & Incrustation \\
\hline $\mathrm{C}$ & 38,73 & 19,38 & 14,13 & 15,1 \\
$\mathrm{O}$ & 19,39 & 18,93 & 40,45 & 31,04 \\
$\mathrm{Si}$ & 12,57 & 39,39 & 15,51 & 29,37 \\
$\mathrm{Al}$ & 0,48 & 5,18 & 4,93 & 8,72 \\
$\mathrm{Ca}$ & 14,33 & - & - & - \\
$\mathrm{Ti}$ & - & - & 13,86 & 5,66 \\
$\mathrm{Fe}$ & - & - & 2,44 & 10,11 \\
\hline
\end{tabular}

As can be seen from Table 5, the incrustations contain larger amounts of elements foreign to poly (dimethyl siloxane), which basically consists of the elements carbon, silicon and oxygen [15], in addition to hydrogen, which is undetectable by this technique. Table 5 also indicates that the incrustations on the samples of new insulators do not contain titanium or iron, unlike the samples of used insulators. These incrustations also revealed the presence of calcium in new insulator samples and the absence of this element in used insulators samples.

Table 6 presents the main results of the thermogravimetric tests on samples of new and used polymer insulators.

Table 6: Thermogravimetric results of samples of new and used polymer insulators

\begin{tabular}{c|c|c|c}
\hline \multirow{2}{*}{ Insulator sample } & Isotherm at $350^{\circ} \mathrm{C}$ & Isotherm at $750^{\circ} \mathrm{C}$ & \multirow{2}{*}{ Residual mass (\%) } \\
\cline { 2 - 4 } & Mass loss $(\%)$ & Mass loss $(\%)$ & \\
\hline New & 14,72 & 34,19 & 51,09 \\
Used & 8,78 & 39,61 & 51,61 \\
\hline
\end{tabular}

Table 7 describes the DSC results, indicating the glass transition $(\mathrm{Tg})$ and crystallization $(\mathrm{Tc})$ temperatures and the crystallization enthalpy of the samples of new and used polymer insulators. 
MANTOVANI, V. A.; FRANCO, C. S; MANCINI, S. D.; HASEAGAWA, H. L.; GIANELLI, G. F.;

BATISTA, V. X.; RODRIGUES, L. L. Revista Matéria, v. 18, n. 04, pp. 1549 - 1562, 2013.

Table 7: DCS results: a glass transition $(\mathrm{Tg})$ and crystallization $(\mathrm{Tc})$ temperatures, and crystallization enthalpy $(\Delta \mathrm{Hc})$ of the new and used polymer.

\begin{tabular}{c|c|c}
\hline Insulator sample & $\mathrm{Tg}$ (glass transition $\left.{ }^{\circ} \mathrm{C}\right)$ & $\Delta \mathrm{Hc}(\mathrm{J} / \mathrm{Kg})$ \\
\hline New & $-71,5$ & 0,948 \\
Used & $-60,9$ & 1,718 \\
\hline
\end{tabular}

As can be seen in Table 7, the glass transition temperature $(\mathrm{Tg})$ of new and used polymer was recorded at temperatures well below room temperature.

Table 8 lists the relative densities determined by displaced liquid of the new and used polymer insulators.

Table 8: Relative densities of the new and used polymer insulators determined by displaced liquid

\begin{tabular}{c|c|c}
\hline Sample & Mean relative density $\left(\mathrm{g} / \mathrm{cm}^{3}\right)$ & Standard deviation $\left(\mathrm{g} / \mathrm{cm}^{3}\right)$ \\
\hline New & 1,5170 & 0,0020 \\
Used & 1,5420 & 0,0010 \\
\hline
\end{tabular}

In the case of relative density (Table 8), the differences appear in the second decimal place, which usually indicates that this property has remained unchanged.

Table 9 lists the contact angles of the polymer insulators, while Figure 9 illustrates water droplets deposited on the surface of a polymer insulator. It shows that the polymer samples have hydrophobic characteristics (contact angle higher than $90^{\circ}$ ).

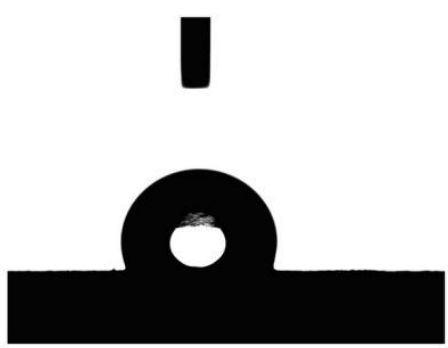

Figure 9: Water droplets deposited on a polymer surface

Table 9: Contact angle of samples of new and used polymer insulators

\begin{tabular}{c|c}
\hline Polymer Sample & Contact angle $\left(^{\circ}\right)$ \\
\hline New & $107,03 \pm 2,21$ \\
Used & $98,71 \pm 3,70$ \\
\hline
\end{tabular}

The results of the solubility test indicated that the insulator samples were not solubilized by any of the solvents used here and normally considered effective for dimethyl siloxane, such as ethyl acetate, chloroform, ethyl ether, toluene and xylene. This suggests that the material must be an elastomeric version of poly (dimethyl siloxane), since intermolecular covalent links (cross-links) prevent dissolution. To verify the feasibility of combustion of the polymeric material, tests were conducted to determine its ash content, whose results are listed in Table 10. 
MANTOVANI, V. A.; FRANCO, C. S; MANCINI, S. D.; HASEAGAWA, H. L.; GIANELLI, G. F.; BATISTA, V. X.; RODRIGUES, L. L. Revista Matéria, v. 18, n. 04, pp. 1549 - 1562, 2013.

Table 10: Ash content of polymer samples

\begin{tabular}{c|c}
\hline Sample & Ash Content, \% (p/p) \\
\hline New & 57,98 \\
sed & 62,27 \\
\hline
\end{tabular}

\section{DISCUSSION}

In the case of ceramic insulators, since the SEM/EDS technique is considered semi-quantitative, the differences in percentage values observed between new and used materials cannot be considered accurate, but the presence or absence of a given element can serve for purposes of comparison. In this regard, the differences (absence of iron in the used sample and calcium in the new one) are probably due to changes in the formulation, raw material, batch, manufacturer, etc., rather than compositional changes during the component's service life. These results indicate that there was no attack by atmospheric elements (pollution), and confirm that the glaze performed its function, i.e., it protected the inner part of the insulator against the entrance of external elements. The cleaning of the samples (item 2.1) carried out prior to the tests may also have contributed to eliminate impurities that may have accumulated on the surface of the insulators.

In terms of composition of glaze of used and new ceramic samples, shows few differences between the samples of new and used insulators. All the samples contained oxygen, potassium, silicon, aluminum and iron, as was expected for a ceramic glaze. The element carbon was not detected in any sample, especially in used ones, which could be a sign of the impregnation of soot and volatile organic compounds such as oil, which could be present in air. Sodium, which could also indicate contact of the insulator with the environment, was also not detected. Again, it should be noted that the samples were cleaned prior to testing.

The contact angle of the samples of ceramic insulators shows that the values of the used samples are smaller than those of the new samples, which characterized by increased hydrophilicity. One explanation for this behavior is that during (or after) the insulator's service life its glaze may become scratched or grooved, in addition to the normal deposits of inorganic elements on its surface [10-12]. Nevertheless, if such deposits occurred, exposure of the insulators' surface to rain and wind may have at least partially removed impregnated contaminants. Cleaning the surface before testing (item 2.1) must have been enough to remove them completely, as observed in the SEM/EDS spectra (Table 2).

In addition, the SEM analysis revealed no defects in the glazes (Figure 4), suggesting that the possibility of surface scratches can also be discarded. Therefore, the differences in contact angle between new and used samples cannot be explained by changes that occurred during the insulators' service life. Again, different compositions resulting from variations in raw material, manufacturer and batch are the likely reasons for these differences.

The XRD spectra of ceramic samples do not show qualitative differences (different peaks), and quantitative information cannot be obtained from these graphs. In general, it appears that the period of time these insulators were in service did not alter the crystalline structure of the material.

By testes of relative density of the ceramic insulators, it can be inferred that the glaze serves to further ensure the reduction of moisture inside the insulator, since its smooth surface and relatively low wettability prevent water absorption. Although the contact angles of the glaze are lower than $90^{\circ}$ (Table 3), characterizing hydrophilicity, they are not as low as those of other highly hydrophilic materials [13-14].

The dilatometric coefficients of thermal expansion slope show a slight increase in the linear expansion coefficient from the new to the used ceramic samples, but there is no evidence that this may have been caused by changes during the use of the insulator. It is possible that this variation is due to differences in the formulation, batch, manufacturer, etc., as mentioned earlier. The phases observed during the dilatometric was not affected during use. These results indicate that the ceramic insulator discarded by the electric power distribution system has good characteristics for use as chamotte, giving the parts dimensional stability.

As with any sintered ceramic material, there is no possibility of new plasticization with water or any other liquid binder after milling, which is why these materials are not recommended for recycling. The reuse of the ground material as chamotte or as aggregate in cement formulations for the construction industry is an interesting and viable alternative for this material [14]. Another possibility is to use this material as crushed gravel for use in the company's substations. According to a previous survey, the amount of discarded ceramic insulators, about 210 tons in 2009, was similar to the quantity of gravel the same company purchased that year for use in its substations [1]. 
It is desirable that insulators be discarded only after its possible uses for the same purpose have been exhausted, which would be indicated by the material's degradation during its service life. In general, the results found for the ceramic insulators suggest that the new ones are replacing used ones which have very similar characteristics, which also suggests similar possible uses. Confirmation of this hypothesis with greater confidence requires specific tests to evaluate their electrical performance.

In the case of polymer insulators, no differences that could indicate possible degradation of the material due to its use were detectable based on a comparison of the infrared spectra of the new and used samples. Because the EDS employed here is a semi-quantitative test, the variation in the values of the atoms does not allow for inferences to be made about the degradation of the used polymer in relation to the new one. The presence of elements other than carbon, oxygen and silicon in both new and used insulators is probably due to the compositions of the initial raw material, particularly incorporated additives such as pigments and fillers. For example, the aluminum detected in the new and used samples probably corresponds to alumina trihydrate (ATH), an additive commonly incorporated in the formulation of insulators to increase their flame resistance [15].

Thermogravimetric results for polymer insulators indicate similar patterns of behavior in samples of used and new insulators in response to heating. The mass loss at $350^{\circ} \mathrm{C}$ is probably attributable to the elimination of the most volatile elements and, in this case, the used sample clearly shows higher thermal stability (lower mass loss). The mass loss in the range of 350 to $750^{\circ} \mathrm{C}$ can be attributed to the elimination all of the carbon from the structure, with the new sample showing greater stability. The difference in behavior in these two regions, at the end of the test, indicates very similar materials with a residual mass of about $51 \%$, which will later be associated with the ash content test results.

As can be seen by DCS results, at the latter temperature (use) there is sufficient energy to move the amorphous phase of the structure, making the material more susceptible to degradation than if it were at temperatures below $\mathrm{Tg}$. Furthermore, the $\mathrm{Tg}$ of the used material is visibly higher than that of the new material, which may be attributed to possible degradation followed by crystallization, since a more crystalline material tends to require more energy to move its residual amorphous phase.

The operating temperature (room temperature) is higher than the crystallization temperature of both new and used insulators (close to $-44^{\circ} \mathrm{C}$ ), which suggests that there is thermal energy to crystallize the material during its use. Considering the occurrence of degradation, it is reasonable to assume that at room temperature there is better packing of smaller chains (which are broken down in degradative processes) interspersed with longer chains.

The values of crystallization enthalpy confirm the higher crystallinity of the used material than the new, suggesting the probable occurrence of degradation. This greater crystallization may have been the reason for the higher thermal stability recorded for the used sample on the thermogravimetric curve at $350^{\circ} \mathrm{C}$ (Table 6). With better packing, the structure tends to expel smaller (more volatile) molecules, resulting in lower variations during heating. The entire discussion about the results of the DSC and thermogravimetry tests (Tables 6 and 7) should be relativized, since it cannot be stated that these materials are exactly of the same grade (e.g., same molar mass, degree of cross-linking, additives, etc.), since compositional differences were detected (Table 5).

The higher density of the used material compared to the new one may also involve a process of degradation, particularly at the surface of used insulators exposed to ultraviolet light, oxygen and water. These elements are known to be degradative agents for polymers, breaking chains, reducing the material's average molecular weight, and inducing increased packing and crystallinity at temperatures above the $\mathrm{Tg}$ and $\mathrm{Tc}$ (Table 7) to which these insulators are subjected [16]. This explanation confirms the DSC and thermogravimetry results, which show that the used material presents higher $\mathrm{Tg}$, crystallinity and thermal stability (up to $350^{\circ} \mathrm{C}$ ).

The contact angle of polymer insulators shows that, unlike the ceramic samples, the surfaces of polymers typically contain non-polar and water repellent elements. This result is consistent with desirable characteristics for an insulator, like was emphasized by Lisboa et al. [17] to avoid stress corrosion cracking (SCC), associated with the existence of flaws in polymeric insulators in the presence of moisture.

The hydrophobicity of used polymers is lower than that of new ones. Nevertheless, because it could not be affirmed unequivocally that the compositional variations determined by EDS/SEM (Table 5) are related to possible contamination from the environment during the insulator's use, the hypothesis that the decrease in the contact angle is related to this fact can be ruled out.

This is because the surfaces of ceramic or polymer insulators, despite the contamination they are subjected to through air pollution, inorganic and organic particulates, etc., are constantly cleaned by the action of rain and wind, which considerably reduces the effect of these contaminants on the contact angle. Since the samples 
were cleaned prior to testing (item 2.1), the possibility that the differences observed are due to the insulators' exposure to the environment is even more unlikely. This discussion is consistent with surface degradation study on polymeric insulators, in which Fontanella et al. [18] observed a decrease in contact angles; however, the hydrophobic behavior was retained.

Like the samples of used ceramic insulators, which also showed a decrease in the contact angle, these differences in the polymer insulators can be attributed to compositional variations due to changes in their formulation, raw material, batch, manufacturer, etc. Nevertheless, in the case of polymer-based insulators, this reduction may also be due to the structural degradation suggested by the results of the thermogravimetric, DSC and relative density tests (Tables 6, 7 and 8). The degraded surfaces of polymeric insulators, which are in constant contact with an electromagnetic field, tends to be more easily subjected to surface electrical tracking, resulting, for example, from high humidity and low precipitation (dew) [2].

Thus, unlike the results obtained from the ceramic material, the test results of the polymeric materials indicate that degradation is likely to occur, which would justify their replacement and discarding as waste by the utility company. Additional tests, such as solubility and ash content, could therefore be performed to verify the recycling potential of this material.

The insolubility of polymer insulators indicates that this material probably cannot be recycled mechanically (i.e., via melting), as is the case of rubbers in general, due to the impossibility of molecular separation obtained through melting. Therefore, what remains for this material is chemical recycling through the chemical and/or thermal breakdown of inter and intramolecular bonds, using specific solvents on equally specific production lines [19], or, as a last resort, energy recovery (burning to reutilize its calorific potential).

The high ash content in polymer insulators was found to be related with the presence of inorganic elements, as suggested by thermogravimetric tests (about 51\%, Table 6) and by SEM/EDS analysis (Table 5). In fact, this result was expected due to the positive identification of the material as poly (dimethyl siloxane), since the main chain of the polymer consists not of carbon (burnable during the test) but of silicon. The ash content of the used sample was found to be higher than that of the new, which may be attributed to the larger amount of inorganic material in the used samples. Whatever the reason for this finding (formulations, molecular weights and different additives, as mentioned in the discussion of Table 5), this material appears to be unsuitable for energy recovery (incineration), which would take advantage of the material's calorific potential. In fact, only about $40 \%$ of its mass is burnable, making it considerably poorer compared to other materials, including carbon-based polymers.

\section{CONCLUSIONS}

Poly (dimethyl siloxane)-based insulators exposed to weather appeared to undergo degradation of their elastomers, contrary to their ceramic counterparts.

The two classes of materials showed compositional differences between new and used insulators, but it cannot be stated these changes were caused by their use. With regard to the new and used ceramic insulators, all the other measured properties (contact angle, relative density, mercury intrusion porosimetry, dilatometry and X-ray diffraction) either showed no differences or the differences that were found could not be attributed to their use. Thus, the replacement of used insulators with new ones appears to be premature, although this should be confirmed through specific electrical performance tests. Once it has been scrapped, the used material exhibits interesting properties for application as chamotte with high thermal stability. It can also be crushed and used in formulations with cement or as a substitute for the gravel that electricity utility companies use in their substations.

As for polymer insulators, the thermogravimetry, DSC and relative density tests suggest degradation of the used material compared to the new. This would justify their substitution for new ones and the scrapping of used insulators. Nonetheless, this waste presents little potential for recycling, whether mechanical (since it is an elastomer, and hence, unmeltable), chemical (which would require reagents and specific recycling lines) or energetic (the material contains only about $40 \%$ of burnable mass).

\section{ACKNOWLEDGEMENTS}

The authors thank Juliana Ziviani, Gabriela Antoniol, Natália Nogueira, Mariana Favero and Raquel Montagnoli for their assistance during the research, and the Agência Nacional de Energia Elétrica (ANEEL, Brazil) for its financial support (Process nos 0390-005/2007, cycle 2006/2007, and execution 2009/2010).

\section{BIBLIOGRAPHY}


[1] MANCINI, S.D., GIANELLI, B.F., BATISTA, V.X., et al., "Oportunidades de Melhoria na Gestão de Resíduos em Empresas Distribuidoras de Eletricidade: o Caso da AES Eletropaulo", Revista Pesquisa e Desenvolvimento da ANEEL 2011, n. 4, pp. 101-103, 2011.

[2] HOCH, DA., MAHATHO, N., BOLONGA F., "Water Induced Discharges on Transmission Voltage Silicone Rubber Insulators." Papers and Publication. UViRCO Technologies. Available from: < http://www.uvirco.com/papers.html > Acess in: 17/07/2012.

[3] AMERICAN SOCIETY FOR TESTING AND MATERIALS, ASTM Standard D 531: Standard Test Methods for Density and Specific Gravity (Relative Density) of Plastics by Displacement, Filadélfia, 2008.

[4] MARK, JE., Polymer Data Handbook, Nova York, Oxford University Press, 1999.

[5] AMERICAN SOCIETY FOR TESTING AND MATERIALS, ASTM Standard E113: Standard Test Methods for Compositional Analysis by Thermogravimetry, West Conshohocken, PA, 2008.

[6] AMERICAN SOCIETY FOR TESTING AND MATERIALS, ASTM Standard D 3418: Standard Test Method for Transition Temperatures and Enthalpies of Fusion and Crystallization of Polymers by Differential Scanning Calorimetry, Filadélfia, 2008.

[7] AMERICAN SOCIETY FOR TESTING AND MATERIALS, ASTM Standard D 5630: Standard Test Method for Ash Content in Plastics, Filadélfia, 2006.

[8] APARISI, J., SÁNCHEZ, L.F., ALBARO, J.L.A., et al., "Obtenção de Recobrimentos Vidrados Brancos e Lisos, para Pavimentos Cerâmicos, a partir de Fritas Isentas de Zircônio", Cerâmica Industrial, v. 6, n.4, pp.7-16, 2001.

[9] SORLÍ, S., TENA, M.A., MESTRE, A., et al., "Efeito da Fase Principal Devitrificada sobre Microestrutura e as Propriedades Mecânicas de Vidrados Cerâmicos”, Cerâmica Industrial, v.10, n.1, pp.7-13, 2005.

[10] PRETTE, A.L.G. Desenvolvimento de esmaltes cerâmicos: aplicação em isoladores elétricos de alto desempenho, Tese de D.Sc., Universidade Federal de Santa Catarina, Florianópolis, SC, Brasil, 2007.

[11] MANO, B.E., MENDES, CL., Introdução a polímeros, São Paulo, Edgard Blüncher LTDA, 2004.

[12] GIANELLI, B.F. Caracterização do efeito corona em isoladores poliméricos do tipo bastão submetidos à poluição salínica. Tese de D.Sc., Universidade Estadual Paulista, Bauru, SP, Brasil, 2008.

[13] ARKLES, B., Hydrophobicity, Hydrophilicity and Silane: Water, water everywhere is the refrain from the rhyme of the ancient mariner and a concern of every modern coatings technologist, Paint \& Coatings Industry, Morrisville, PA, Out. 2006. Available from: <

http://www.gelest.com/goods/pdf/Library/advances/HydrophobicityHydrophilicityandSilanes.pdf $>$. Acess in: 20/03/20012.

[14] KIM, J., CHAUDHURY, M.K., OWEN, M .J., Hydrophobicity Loss and Recovery of Silicone HV Insulation, IEEE Transactions on Dielectrics and Electfical Insulation, v.6, n.5, pp. 695-702, 1999.

[15] PORTELLA, K.F., JOUKOSKI, A., FRANCK, R., et al.,“Reciclagem secundária de rejeitos de porcelanas elétricas em estruturas de concreto: determinação do desempenho sob envelhecimento acelerado", Cerâmica, v.52, n. 323, pp.155-167, 2006.

[16] REICH, L., STIVALA, S.S., Elements of Polymer Degradation, Nova Iorque, McGraw-Hill, 1971.

[17] LISBOA, M.B., FURTADO, H.C., OLIVEIRA, W.P., “Análise de falha em isolador polimérico”, Matéria, v. 16, n.4, pp.811-818, 2011.

[18] FONTANELLA, C.A., OLIVEIRA, A.P.N., HOTZA, D., "Recobrimentos poliméricos hidrofóbicos sobre isoladores elétricos de porcelana"., Matéria, v.13, n.4, pp.624-635, 2008.

[19] OKU, A, HUANG, W, IKEDA, Y., "Monomer recycling for vulcanized silicone rubbers in the form of cyclosiloxane monomers: role of acid buffers", Polymer, n.43, v.26, pp.7289-7293, 2002. 